\title{
REVISITANDO A LAPA DO SUMIDOURO: MARCO PALEO-ANTROPOLÓGICO DO QUATERNÁRIO AMERICANO
}

\author{
LUÍS B. PILÓ \\ Depto. de Biologia, IB, USP, Rua do Matão, 227, 05508-900, São Paulo, SP, Brasil.lpilo@uai.com.br \\ AUGUSTO S. AULER \\ IGC, UFMG, Av. Antônio Carlos, 6627, 31270-901, Belo Horizonte, MG, Brasil. aauler@zaz.com.br \\ WALTER A. NEVES \\ Depto. de Biologia, IB, USP. Rua do Matão, 227, 05508-900, São Paulo, SP, Brasil. waneves@ib.usp.br \\ XIANFENG WANG \\ Department of Geology \& Geophysics, University of Minnesota, Minneapolis, MN 55455, USA.wang0452@tc.umn.edu \\ HAI CHENG \\ Department of Geology \& Geophysics, University of Minnesota, Minneapolis, MN 55455, USA. cheng021@gold.tc.umn.edu \\ R. LAWRENCE EDWARDS \\ Department of Geology \& Geophysics, University of Minnesota, Minneapolis, MN 55455, USA. edwar001@umn.edu
}

\begin{abstract}
RESUMO - Com o objetivo de contextualizar e rediscutir as principais interpretações relacionadas a este importante sítio, a Lapa do Sumidouro foi revisitada e foram realizados estudos topográficos, sedimentológicos e tafonômicos. Idades pela série ${ }^{230} \mathrm{Th} /{ }^{234} \mathrm{U}$ e ${ }^{14} \mathrm{C}$ registraram dois episódios de sedimentação terrígena: um mais antigo que 238.000 anos e outro mais jovem que 11.000 anos. Dois episódios de sedimentação química foram identificados, sendo o mais antigo em torno de 240.000 anos e outro por volta de 11.000 a 8.000 anos. Duas fases erosivas foram constatadas. A entrada sul foi identificada como a mais favorável para a introdução de corpos humanos na caverna. Os ossos de animais da fauna extinta e vivente teriam penetrado, principalmente, pela entrada norte, via sumidouro. Uma idade mínima de 8.000 anos foi registrada para ossos humanos e para fauna extinta, comprovando as idéias prévias sobre a grande antiguidade desses remanescentes para a região de Lagoa Santa e para a América.
\end{abstract}

Palavras-chave: Sedimentação em caverna, Homem de Lagoa Santa, tafonomia, Quaternário.

ABSTRACT - REVISITING LAPA DO SUMIDOURO, A CLASSIC PALEOANTHROPOLOGICAL SITE OF THE AMERICAN QUATERNARY. In order to gather new data and discuss the hypothesis related to this important site, the Lapa do Sumidouro was visited and detailed sedimentological and taphonomical studies have been performed. U-series and radiocarbon ages point towards two events of terrigenous sedimentation; older than 238,000 yr and after 11,000 yr. Two events of chemical sedimentation were identified, the earlier being around $240,000 \mathrm{yr}$ and a younger one around 11,000-8,000 yr. Two erosion phases were also identified. We interpret human remains to have been emplaced via the dry southern entrance, while input of non human bones occurred through the northern swallet entrance. A minimum age of 8,000 yr was obtained for some human and animal bones, confirming previous view of considerable antiquity for these remains for the Lagoa Santa region and America..

Key words: Cave sedimentology, Lagoa Santa Man, taphonomy, Quaternary.

\section{INTRODUÇÃO}

Em setembro de 1843 o naturalista dinamarquês Peter Wilhelm Lund, considerado o pai da paleontologia brasileira, explorou a Lapa do Sumidouro, na região cárstica de Lagoa Santa, em Minas Gerais. Baseado em observações espeleogenéticas, incluindo análises hidrológicas, estratigráficas e tafonômicas, Lund apresentou uma tese pioneira e ousada para o continente americano: a convivência do homem pré-histórico com os grandes mamíferos extintos. $\mathrm{Na}$ época, essa possibilidade ainda não havia sido cogitada pela comunidade científica. 
Sua tese foi intensamente debatida na Europa e na América do Norte ainda na segunda metade do século XIX e início do século XX (Quatrefages, 1881; Lütken, 1883; Kate, 1885; Reinhardt, 1888; Hansen, 1888; Rivet, 1908). A maioria dos autores questionou esta tese, particularmente devido às condições nas quais os ossos humanos e os de animais foram encontrados e associados. O ponto focal das críticas foi a ocorrência de inundações periódicas na caverna devido à existência de um sumidouro, o que certamente teria revolvido, em diversas ocasiões, os estratos sedimentares e os ossos ali depositados. A semelhança do grau de fossilização dos ossos de animais extintos e humanos, outro argumento utilizado por Lund, também foi questionada, pois alguns ossos de espécies ainda viventes apresentavam-se fossilizados, sendo, nesse caso, injustificável relacionar grau de fossilização e idade dos ossos (para uma revisão ver Hrdlicka, 1912). Desde de então, a Lapa do Sumidouro tornou-se um sítio clássico para os estudos dos paleoíndios americanos. A coleção de ossos humanos coletados por Lund está depositada no $\mathrm{Mu}$ seu Zoológico da Universidade de Copenhague (MZUC) e continua sendo objeto de análise (Neves \& Pucciarelli, 1991; SotoHeim,1994; Powell \& Neves, 1999; Blum \& Neves, 2002).

Aproveitando as condições climáticas e hidrológicas que os anos de 2001 e 2002 proporcionaram à caverna (rebaixamento do lençol freático e esvaziamento dos condutos), a Lapa do Sumidouro foi investigada, com o intuito de contextualizar e rediscutir as principais interpretações de Lund relacionadas aos registros sedimentares, fossilíferos, tafonômicos e cronológicos.

\section{MÉTODOS E TÉCNICAS}

Inicialmente foi realizada uma análise da documentação elaborada por Lund sobre a Lapa do Sumidouro, visando resgatar as interpretações elaboradas pelo autor em 1844. A análise foi concentrada em duas traduções para o português da carta intitulada Notícia sobre ossadas humanas fósseis achadas numa caverna do Brasil (Paula Couto, 1950; Holten \& Sterll, 1999).

Em seguida foi realizada uma exploração espeleológica elaborando a topografia da caverna. Para análise de aspectos da dinâmica sedimentar da caverna, foram estabelecidas sete seções morfo-sedimentares em seus condutos. Essas seções foram concentradas nos setores da caverna onde os sedimentos não foram intensamente erodidos: os salões Lund e Hélio Diniz. Diniz, que também escavou a Lapa do Sumidouro em 1956, não publicou seus trabalhos, sendo impossível localizar com precisão onde ocorreram suas intervenções. Procurou-se analisar as fácies sedimentares e colunas estratigráficas não alteradas pelas escavações de Lund e Diniz. Foi amostrado somente um sedimento remexido do piso do salão Lund para efeito de comparação química com os demais.

Os sedimentos foram analisados através de fácies descritivas, mediante critérios granulométricos, estruturais e de cor, que seguiram os códigos do Munsell Soil Color Charts. Em seguida foram coletados sedimentos clásticos das sete seções para análises químicas por fluorescência de raios-X (fusão com tetraborato de lítio). Três amostras de calcita secundária foram coletadas para datações ${ }^{230} \mathrm{Th} /{ }^{234} \mathrm{U}$, via TIMS (Thermal Ionisation Mass Spectrometry) e ICP-MS (Inductively Coupled Plasma Mass Spectrometry).

Após a análise de 1.337 peças da coleção de Brechas de cavernas (Lund, 1845) da região de Lagoa Santa, foi selecionada uma amostra da Lapa do Sumidouro com qualidade técnica para datações ${ }^{230} \mathrm{Th} /{ }^{234} \mathrm{U}$ e ${ }^{14} \mathrm{C}$ - AMS (Accelerator Mass Spectrometry). Durante o exame da coleção de esqueletos humanos exumados por Lund, no Sumidouro, foram obtidas mais duas amostras para datações ${ }^{14} \mathrm{C}$ (AMS): um pequeno fragmento de carvão vegetal incrustado em um osso longo e uma pequena concha lacustre cimentada no meato auditivo de um crânio da coleção.

Tentativas anteriores de datar por AMS fragmentos de ossos e dentes humanos e de ossos de megafauna do Sumidouro mostraram-se infrutíferas pela total ausência de colágeno nessas amostras.

\section{PETER LUND NA LAPA DO SUMIDOURO}

Peter Lund visitou a Lapa do Sumidouro em 1839, 1840 e 1841, mas foi entre 29 de agosto e 10 de setembro de 1843 , aproveitando uma forte estiagem que ocasionou o esvaziamento da lagoa do Sumidouro, que teve a oportunidade de efetuar uma escavação mais sistemática. Em 1840, a mesma caverna já tinha possibilitado o achado de restos de animais e os dois primeiros crânios humanos de suas pesquisas, que apresentavam alto grau de fossilização e "extraordinária idade”, descartando qualquer possibilidade de interpretação das idades desses restos misturados, por não se encontrarem em sua camada primitiva (Lund, 1844: 466).

Lund tinha ciência que somente um estudo das camadas sedimentares fossilíferas poderia lhe fornecer "alguma esperança de encontrar informações sobre um assunto tão importante como a idade do ser humano neste continente" (Lund, 1844: 466). Vários tipos de sedimentos foram descritos e analisados, juntamente com seus respectivos fósseis (Tabela 1). Foram encontrados "pelo menos 30 indivíduos humanos de várias idades, desde recém nascidos até velhos caducos" (Lund, 1844: 468). À exceção da argila vermelha primitiva, Lund exumou ossos humanos em todos os tipos de sedimentos. Ossos de animais foram identificados em todos os sedimentos (Lund, 1844). Segundo o naturalista, o sedimento vermelho tinha as mesmas características do "velho aterro das cavernas” (Lund, 1844: 478) - sedimento que teria preenchido originalmente a caverna e deveria ser considerado como resto do mesmo. Esses sedimentos não tinham sido influenciados pelas águas que penetraram na caverna. Todos os demais sedimentos seriam filiados a essa argila vermelha, mas influenciados, em graus diferentes de intensidade, pelas águas do lago existente no interior da caverna. Nesses sedimentos alterados pelas oscilações do lago interno, a cor vermelha ia se transformando em outras cores e o número de conchas aumentando. $\mathrm{O}$ sedimento amarelo com manchas pretas indicava a segregação química de minerais contendo ferro. Nesse sedimento, os ossos também apresentavam um avançado grau de fossilização. Isso demonstrava, segundo Lund, 
Tabela 1. Sedimentos, fósseis e diagênese descritas por Lund (1844).

Table 1. Sediment types, fossils and diagenetic features according to Lund (1844).

\begin{tabular}{|c|c|c|}
\hline Tipo de sedimento & Fósseis & Diagênese \\
\hline $\begin{array}{l}\text { Argila do fundo do lago } \\
\text { (sedimento revolvido e mais } \\
\text { recente). }\end{array}$ & $\begin{array}{l}\text { Poucos ossos humanos, morcegos, roedores, } \\
\text { puma, marsupiais, lobo troglodita, preguiça } \\
\text { extinta, pequeno chacal, lontra, tatus, } \\
\text { crocodilo, jaguatirica, jaguar fóssil, porco-do- } \\
\text { mato, aves e peixes. }\end{array}$ & $\begin{array}{l}\text { Maioria dos ossos petrificado de cor castanho } \\
\text { avermelhado ou negro; apresentava polimento } \\
\text { metálico; morcegos quase frescos; peixes mais ou } \\
\text { menos petrificados. }\end{array}$ \\
\hline $\begin{array}{l}\text { Terra negrusca ou tapete de } \\
\text { húmus (sedimento revolvido e } \\
\text { mais recente). }\end{array}$ & $\begin{array}{c}\text { Ossos humanos, morcegos, roedores, } \\
\text { jaguatirica, lobo troglodita, jaguar, porco-do- } \\
\text { mato, cervo, tatus, aves, crocodilo, preguiça } \\
\text { extinta e peixes. }\end{array}$ & $\begin{array}{c}\text { Maioria mais ou menos petrificada, exceto, alguns } \\
\text { peixes e morcegos que se encontravam mais ou } \\
\text { menos frescos. }\end{array}$ \\
\hline $\begin{array}{l}\text { Argila cinza amarelada com } \\
\text { conchas - localmente brechas }\end{array}$ & & \\
\hline $\begin{array}{l}\text { de ossos e capa estalagmítica. } \\
\text { (sedimento original da caverna, } \\
\text { modificado pela atuação do } \\
\text { lençol freático). }\end{array}$ & $\begin{array}{l}\text { Muitos ossos humanos, lhama, preguiça } \\
\text { extinta, capivara fóssil, porco-do-mato, cervo } \\
\text { (puma e jaguatirica na brecha de ossos). }\end{array}$ & $\begin{array}{l}\text { Parcialmente petrificado na argila e petrificado no } \\
\text { interior da matriz da brecha de ossos. }\end{array}$ \\
\hline $\begin{array}{l}\text { Argila amarelada com manchas } \\
\text { pretas }\end{array}$ & & \\
\hline $\begin{array}{l}\text { (sedimento original da caverna, } \\
\text { modificado pela atuação do } \\
\text { lençol freático). }\end{array}$ & $\begin{array}{c}\text { Diversos ossos humanos, macaco fóssil, lobo } \\
\text { guará, porco-do-mato, roedores, Ihama, } \\
\text { jaguar fóssil e cavalo extinto. }\end{array}$ & $\begin{array}{l}\text { Em parte petrificados e com manchas pretas, } \\
\text { semelhantes às encontradas no sedimento. }\end{array}$ \\
\hline $\begin{array}{l}\text { Argila vermelha } \\
\text { (sedimento original da caverna). }\end{array}$ & Duas espécies de cervos. & Parcialmente petrificados. \\
\hline
\end{tabular}

que esse sedimento e seus respectivos fósseis tinham passado por um período muito longo sem o seu revolvimento pela água. Analisando a argila amarelada com manchas pretas Lund foi decisivo: "Foi nessa mistura de espécies extintas e ainda vivas que apareceram os restos enigmáticos do cavalo e do homem, todos no mesmo estado de transformação, de modo a não deixar nenhuma dúvida sobre a coexistência desses seres cujos restos foram enterrados juntos" (Lund, 1844: 480).

Nas camadas inferiores, ocorria uma transição quase imperceptível para um sedimento amarelo-acinzentado sem manchas, mas com grande conteúdo de conchas. Uma crosta estalagmítica também foi identificada, localmente, sobre esse sedimento, que continha a maior parte dos ossos humanos, como também restos da fauna extinta (Lund, 1844). Os sedimentos de húmus e a argila do fundo do lago, abundantes em conchas, foram interpretados como originados da introdução recente de sedimentos, não sendo filiados à argila vermelha. A tese proposta por Lund foi constituída sobre bases sedimentológicas e estratigráficas discutíveis, já que, conforme ele mesmo reconhecia, ossos de idades diferentes poderiam ter sido removidos de seus locais de deposição primária e misturados nas argilas transformadas.

Lund (1844) também formulou hipóteses sobre como os ossos teriam entrado na caverna. As seguintes causas podem ter tido alguma participação na presença de ossos de animais na Lapa do Sumidouro: o arraste de presas por predadores; a ocasional queda de animais pelas fendas na caverna; o ocasional extravio, nos corredores escuros das cavernas, de ani- mais à procura de abrigo ou do salitre que é encontrado na superfície do solo; animais que adotavam as cavernas como moradia ou que as visitavam freqüentemente e; 5) carreamento de cadáveres e restos esqueletais pelo fluxo da água vinda de fora.

Quanto aos ossos humanos, Lund (1844) relata que os indivíduos velhos e as crianças mortas foram colocados na caverna, que serviu de cemitério local. Lund reconheceu ossos humanos articulados tendo, no entanto, destacado que a maioria dos ossos estava fraturada e tinha sido espalhada, desordenadamente, pela água. Ainda, alguns indivíduos teriam sido mortos por golpes aplicados à têmpora (Lund, 1844), sugerindo a ocorrência de um massacre.

\section{REVISITANDO A LAPA DO SUMIDOURO}

\section{Aspectos espeleológicos e hidrológicos}

A Lapa do Sumidouro está localizada na região cárstica de Lagoa Santa, a aproximadamente $40 \mathrm{~km}$ ao norte de Belo Horizonte, Estado de Minas Gerais (Figura 1). A caverna encontrase na base de um maciço calcário do Grupo Bambuí (Neoproterozóico) posicionado na extremidade leste da lagoa do Sumidouro, apresentando um desenvolvimento horizontal de $650 \mathrm{~m}$ e um desnível total de $15 \mathrm{~m}$.

A caverna está conectada com a superfície do relevo através de duas entradas (Figura 2), denominadas norte e sul. A entrada norte apresenta-se como um sumidouro da lagoa do Sumidouro. Essa lagoa cárstica apresenta grandes flutuações 


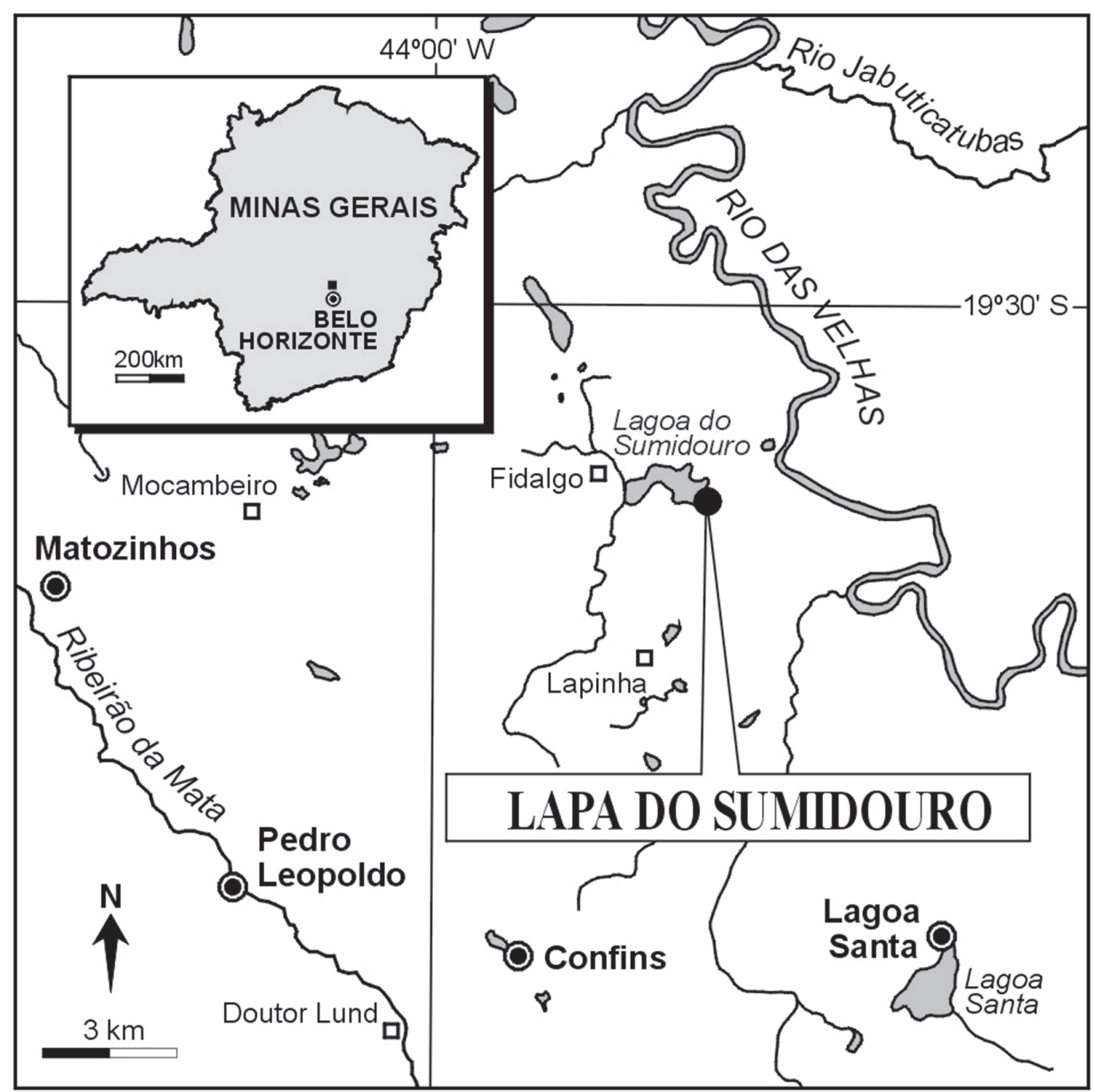

Figura 1. Localização da Lapa do Sumidouro.

Figure 1. Location map of the Lapa do Sumidouro.

de seu lençol freático, que pode oscilar até $14 \mathrm{~m}$. Quando a lagoa encontra-se no seu nível mínimo, as águas de um pequeno córrego (Samambaia), que a alimenta, são introduzidas no carste subterrâneo por um conduto impenetrável entulhado de blocos abatidos. Esse fluxo hídrico não é direcionado para a Lapa do Sumidouro, tendo sua rota posicionada em nível inferior (impenetrável ao homem). Com a elevação da ordem de $6 \mathrm{~m}$ no nível da lagoa a entrada norte torna-se um sumidouro funcional, inundando os condutos e salões da caverna. O fluxo da água apresenta uma direção N-S. A entrada sul, posicionada $7 \mathrm{~m}$ acima, só é atingida integralmente pela água quando a lagoa está no seu nível máximo, em casos de cheias excepcionais.

Mesmo quando o nível da lagoa está muito baixo, a Lapa do Sumidouro apresenta o afloramento do lençol freático (lago hipógeo), particularmente, no denominado salão Lund. Medidas de condutividade elétrica realizadas em setembro de 2001 indicaram valores muito distintos entre as águas da lagoa e do lençol freático da caverna. Essas águas se mesclam somente no início do funcionamento do sumidouro da lagoa (entrada norte).

Em planta, a Lapa do Sumidouro apresenta um conjunto de condutos anastomóticos (tubos curvilíneos), que se interconectam, formando um labirinto superimposto por fraturas L-W de alto ângulo e pela atitude da laminação do calcário. Segundo Palmer (1991), o padrão anastomótico representa cavernas com recargas via depressão cárstica, com o predomínio de dissolução nas estruturas planares.

Cortes transversais mostram condutos circulares, elípticos e fendas alargadas, dependendo do arranjo da porosidade secundária, caracterizando uma cavidade originada a partir das flutuações do lençol freático. Os condutos superiores, constituídos por fendas alargadas, podem ter sofrido ação de regime vadoso. Processos de abatimentos de tetos e paredes ocorreram em uma fase mais tardia da história evolutiva da caverna.

\section{Depósitos clásticos e químicos da caverna}

Para a análise dos registros sedimentares na Lapa do Sumidouro foram elaboradas sete seções morfo-sedimentares (Figura 3). Os dados obtidos a partir da análise dos sedimentos da caverna possibilitaram a associação e a individualização de seis fácies, ou seja, sedimentos que possuem variação restrita de relações entre si (Laureano, 1998; Kos, 2001). 


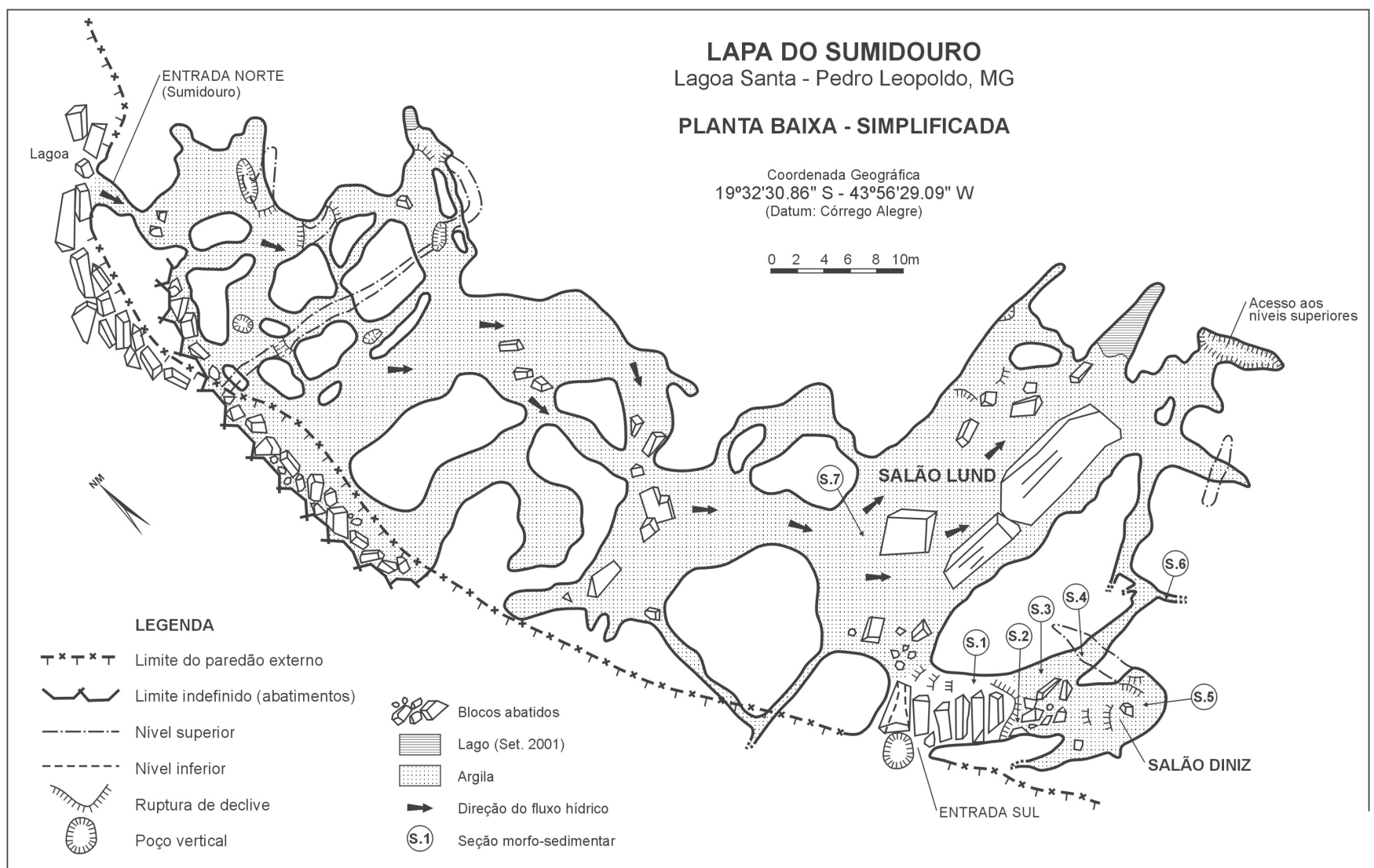

Figura 2. Planta baixa da Lapa do Sumidouro.

Figure 2. Plan map of the Lapa do Sumidouro.

\section{Descrição das fácies sedimentares}

Fácies A - Brecha de grânulos (Bgr). Essa fácies foi identificada nas seções 1 e 2, sendo constituída por uma brecha suportada de grânulos líticos (Bgr). Os grânulos são constituídos por quartzo mal selecionado, subangular a subarredondado. Nódulos duros de argila também estão presentes. A cor da matriz é 7.5YR 7/8 (amarelo-avermelhado). A consistência é extremamente dura, devido à cimentação por calcita.

Fácies B - Brecha de seixos (Bse). Essa fácies foi identificada na seção 1 , sendo constituída por uma brecha suportada de seixos líticos (Bse). Os clastos, constituídos por seixos de quartzo subarredondados e subangulares, são mal selecionados. Fragmentos milimétricos de filito alterado também foram identificados. A matriz lamosa apresenta cor 7.5YR 6/8 (amarelo-avermelhado), como também manchas escuras localizadas, ocasionadas pela precipitação de óxidos. A cimentação da calcita está presente, dando uma consistência extremamente dura ao sedimento.

Fácies C - Lama maciça amarela com manchas pretas (Lma). A fácies C está presente nas seções 1, 2, 3, 4 e 6, sendo constituída por lama maciça de cor 10YR 6/8 e 7/8 (amarelo). Essa matriz lamosa apresenta importantes concentrações de $\mathrm{Fe}_{2} \mathrm{O}_{3}$, as quais imprimem diversas manchas pretas ao testemunho sedimentar, principalmente nas seções 2, 3 e 6. Ocorrem vênulas de percolação de calcita e óxidos de ferro. Nas outras duas seções (1 e 4), as concentrações de ferro são incipientes. À exceção da Lma encontrada na seção 4 , a consistência da Lma é, no conjunto, extremamente dura, em função da forte cimentação carbonática, que se apresenta homogênea.

Fácies D - Lama laminada vermelha (Llv). Essa fácies foi identificada nas seções 1, 2, 3 e 4. Destaca-se uma lama laminar vermelha (2.5YR5/8). A matriz, muito homogênea, apresentou uma consistência dura nas seções 1,2 e 3, ocasionada pela cimentação por calcita. Destacam-se vênulas de percolação de calcita e de óxidos de ferro. Na seção 4, a Llv apresentou uma consistência macia. A laminação plano-paralela, impressa em todos os testemunhos sedimentares dessa fácies, é representada pela alternância de granulações (argila e silte).

Fácies E - Areia lamosa com clastos (Alc). Essa fácies ocorre somente na seção 5. Na matriz arenosa predomina a cor 2.5YR 5/8 (vermelho). A laminação plano-paralela, apesar de nítida, apresenta-se obliterada pela cimentação calcítica. Os clastos, suportados pela matriz arenosa, são constituídos principalmente por grânulos e seixos angulares de quartzo. Os clastos são mal selecionados. Fragmentos milimétricos de filito foram identificados.

Fácies F - Areia lamosa com bioclastos (Alb). A fácies F foi registrada em dois sítios deposicionais, localizados no salão onde Lund escavou os remanescentes humanos e de animais da fauna extinta e viventes. Na seção 7 o sedimento analisado foi coletado a $50 \mathrm{~cm}$ de profundidade do piso. A outra amostra (ref. 789) foi identificada na coleção de brechas que integra o acervo do MZUC (Figura 4). No Catálogo 

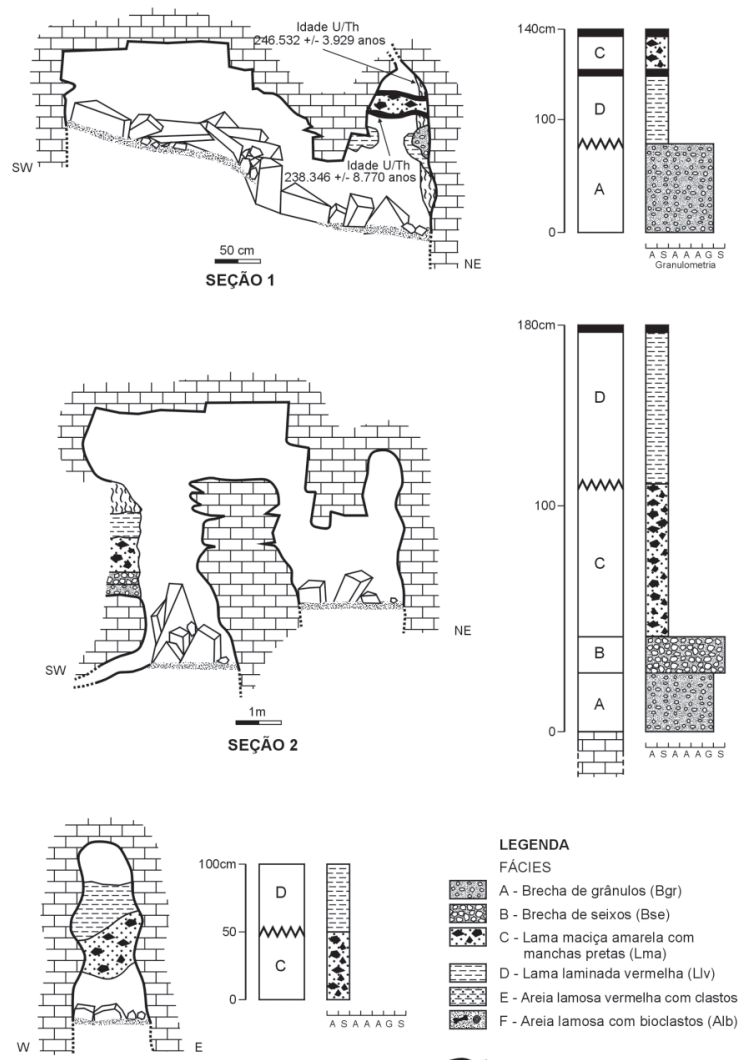

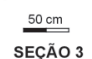

A

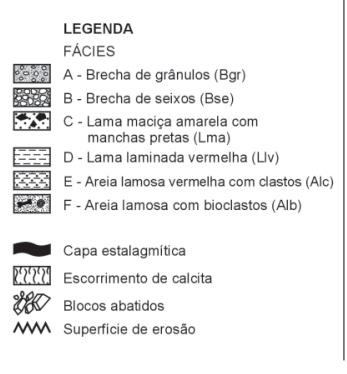

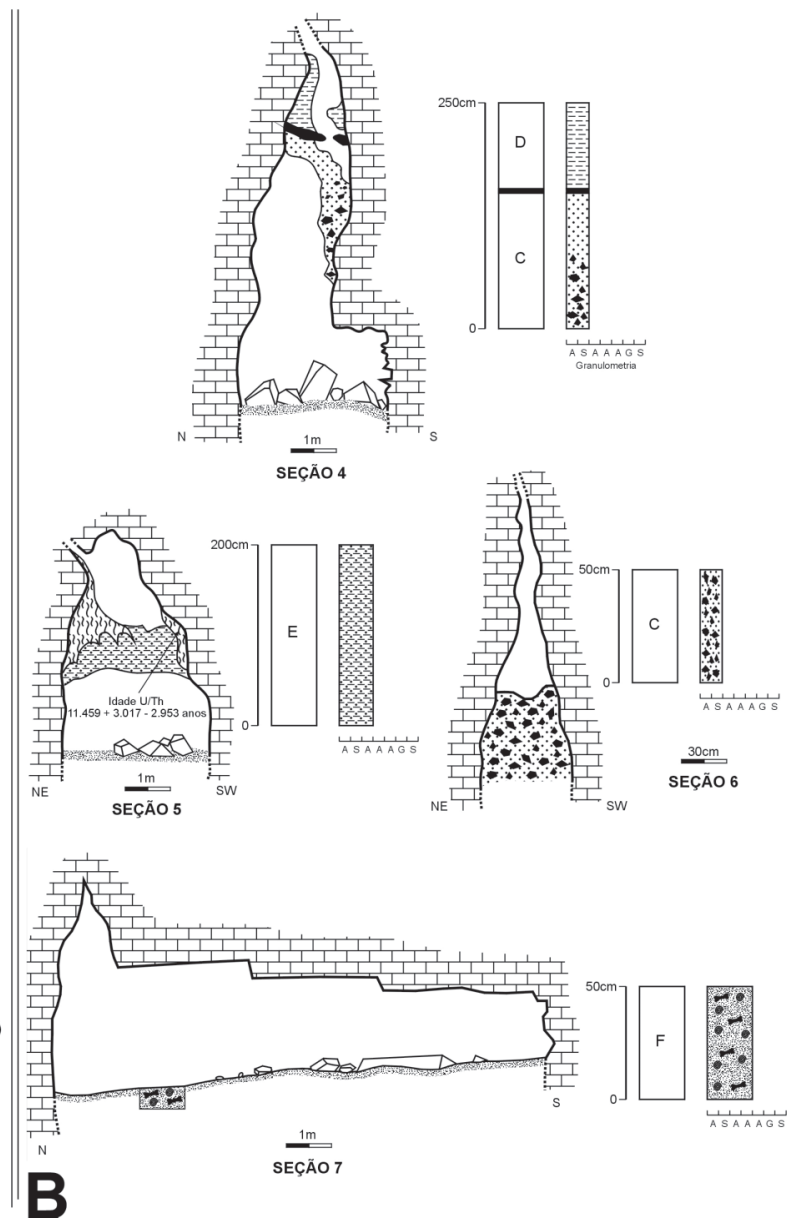

Figura 3. Seções morfo-sedimentares, colunas estratigráficas e granulometria das fácies sedimentares da Lapa do Sumidouro.

Figure 3. Morphological and sedimentological sections, stratigraphical columns and granulometry of the sedimentary facies at Lapa do Sumidouro.

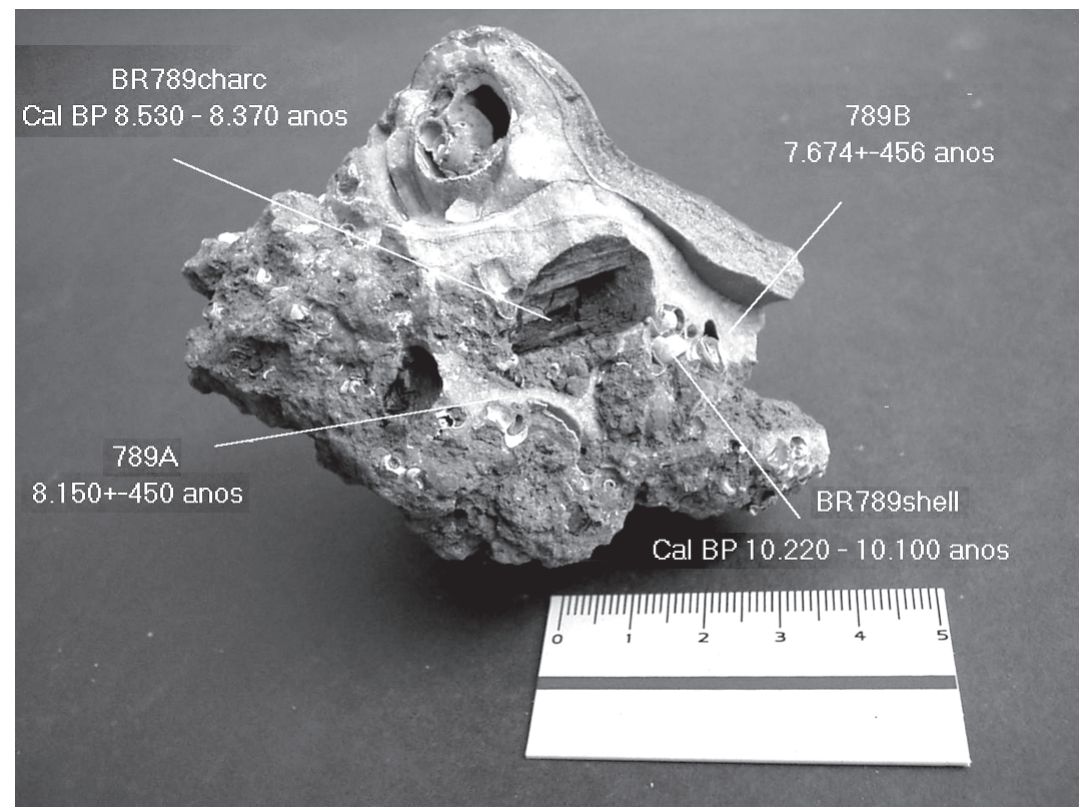

Figura 4. Amostra 789 indicando o local da retirada das amostras para datação.

Figure 4. Sample 789 indicating subsampling sites for dating. 
de Brechas Lund descreve essa amostra como uma brecha marrom amarelada com crosta estalagmítica contendo ossos, além de grande número de concha (Lund, 1845). Essa fácies é constituída por areia lamosa maciça com bioclastos (Alb). A cor predominante na amostra da seção 7 é 10YR 5/6 (bruno amarelado). Na amostra 789 a cor é amarela avermelhada (7,5YR 6/8). Localmente ocorrem manchas escuras em decorrência da segregação do ferro, principalmente nos sedimentos da seção 7. Fragmentos milimétricos a centimétricos de ferricrete podem ser identificados na matriz areno-siltosa dessa seção. Os bioclastos milimétricos estão representados por conchas, bem distribuídas, sem gradação e sustentadas pela matriz. Fragmentos milimétricos a centimétricos de carvão vegetal e de ossos fraturados foram identificados na seção 7. A cimentação é elevada, ocasionando uma consistência muito dura.

\section{Análise química dos sedimentos}

$\mathrm{Na}$ fácies C (Lma), registrada nas seções 2,3 e 6, as porcentagens obtidas para os óxidos apresentaram grande similaridade (Tabela 2). A ocorrência expressiva do $\mathrm{Fe}_{2} \mathrm{O}_{3}$ na forma de mosqueados (manchas pretas) testemunha um regime de saturação hídrica sazonal, para mobilizar e reoxidar o ferro.

Na seção 1, a Lma apresentou um valor baixo (7\%) para o alumínio se comparado às demais Lma, o mesmo ocorrendo com a percentagem de $\mathrm{Fe}_{2} \mathrm{O}_{3}(4,2 \%)$. O valor de $\mathrm{CaO}$, por sua vez, é o mais alto, com $25,6 \%$. A baixa segregação do ferro indica que as oscilações do lençol freático não atingem com freqüência esses sedimentos após a sua deposição (topograficamente em posição mais alta). A forte cimentação observada nessa amostra está relacionada à percolação e à precipitação de águas ricas em carbonato de cálcio, que originaram uma capa estalagmítica sobre a referida fácies. Na seção 4, a Lma registrou valores de sílica e de alumínio superiores às demais. A porcentagem de cálcio é muito baixa $(0,54 \%)$, indicando uma baixa atuação do lençol freático nesse sedimento, que se en- contra, altimetricamente, em posição mais elevada.

A fácies D (Llv), identificada nas seções 1, 3 e 4, também apresenta grande semelhança quanto aos valores de $\mathrm{SiO}_{2}$, $\mathrm{Al}_{2} \mathrm{O}_{3}$ e $\mathrm{Fe}_{2} \mathrm{O}_{3}$ A Llv da seção 2, por sua vez, apresentou maior lixiviaçã̃o de $\mathrm{SiO}_{2}$ e maiores valores de $\mathrm{CaO}$. Isso pode ser explicado pela maior exposição da Lmv dessa seção às flutuações do lençol freático, já que essa se encontra em posição altimétrica inferior às demais.

Os dados químicos também demonstraram uma diferenciação entre os teores de óxidos encontrados nas fácies $\mathrm{C}$ (amarela) e D (vermelha). Na fácies amarela a $\mathrm{SiO}_{2}$ apresenta-se nitidamente mais lixiviada que na fácies vermelha. A seção 4 demonstra que as duas fácies já foram introduzidas na caverna, via epicarste, com diferenciações químicas claras. Os dados químicos sugerem que os sedimentos lamosos amarelos e vermelhos analisados não compartilham uma mesma origem, como defendeu Lund, em 1844.

A fácies $\mathrm{E}$ (Alc), também de cor vermelha, apresentou menores porcentagens de $\mathrm{SiO}_{2}, \mathrm{Al}_{2} \mathrm{O}_{3}$ e $\mathrm{Fe}_{2} \mathrm{O}_{3}$ que a outra fácies vermelha (C), indicando outra fonte de origem. Os dados químicos indicam que existem pelo menos duas fácies vermelhas na caverna.

A fácies $\mathrm{F}(\mathrm{Alb})$, representada no piso do salão escavado por Lund (Seção 7), apresentou características químicas distintas das demais fácies analisadas, indicando um grau elevado de lixiviação da sílica. Por outro lado, essa fácies demonstrou porcentagens elevadas de óxidos neoformados, particularmente $\mathrm{Fe}_{2} \mathrm{O}_{3}$ e MnO.

Os sedimentos das cavernas e dos solos da região são originados, principalmente, da alteração dos filitos, que na estratigrafia regional estão assentados sobre os calcários (Lund, 1844; Piló, 1998). Análises químicas de três amostras de filito alterado da região indicaram uma média de $65,9 \%$ de $\mathrm{SiO}_{2}$, $17,2 \%$ de $\mathrm{Al}_{2} \mathrm{O}_{3}$ e $8,3 \%$ de $\mathrm{Fe}_{2} \mathrm{O}_{3}$ (Piló, 1998), que, comparados

Tabela 2. Análises químicas dos sedimentos. Valores em percentagem (\%).

Table 2. Chemical analyses of the sediments. Values in percentage (\%).

\begin{tabular}{l|cccccccccc}
\hline Amostras & $\mathrm{SiO}_{2}$ & $\mathbf{A l}_{2} \mathrm{O}_{3}$ & $\mathrm{TiO}_{2}$ & $\mathrm{Fe}_{2} \mathrm{O}_{3}$ & $\mathrm{MnO}$ & $\mathrm{MgO}$ & $\mathrm{CaO}$ & $\mathrm{Na}_{2} \mathrm{O}$ & $\mathrm{K}_{2} \mathrm{O}$ & $\mathrm{P}_{2} \mathrm{O}_{5}$ \\
\hline Seção 1 - A & 46,7 & 5,4 & 0,28 & 5,5 & 0,21 & 0,91 & 21,4 & $<0.1$ & 0,87 & 0,15 \\
Seção 1 - C & 35,9 & 7 & 0,35 & 4,2 & 0,16 & 1,3 & 25,6 & $<0.1$ & 1,7 & 0,36 \\
Seção 1 - D & 63,6 & 13,6 & 0,71 & 6,8 & 0,25 & 1,5 & 1 & $<0.1$ & 2,2 & 0,19 \\
Seção 2 - A & 48 & 9,9 & 0,49 & 6,3 & 0,06 & 0,73 & 15,8 & $<0.1$ & 0,69 & 0,18 \\
Seção 2 - B & 49,6 & 6,1 & 0,37 & 10,9 & 0,8 & 1 & 14,3 & $<0.1$ & 1 & 0,42 \\
Seção 2 - C & 32,8 & 13,1 & 0,67 & 10,8 & 0,97 & 0,89 & 18,5 & 0,2 & 1,2 & 0,45 \\
Seção 2 - D & 36,1 & 11,5 & 0,58 & 8,7 & 0,46 & 1,5 & 18,2 & $<0.1$ & 1,7 & 0,72 \\
Seção 3 - C & 29,7 & 13 & 0,57 & 18,6 & 1,5 & 1,2 & 14,7 & $<0.1$ & 1,6 & 0,77 \\
Seção 3 - D & 67,4 & 13,2 & 0,67 & 6,8 & 0,12 & 1,4 & 0,54 & $<0.1$ & 2,2 & 0,17 \\
Seção 4 - D & 67,7 & 12,9 & 0,66 & 6,5 & 0,04 & 1,6 & 0,27 & 0,18 & 2,2 & 0,25 \\
Seção 4 - C & 49,1 & 20,5 & 0,95 & 12,7 & 0,09 & 2,1 & 0,57 & $<0.1$ & 3,2 & 0,7 \\
Seção 5 - E & 45,1 & 8,2 & 0,44 & 4,2 & 0,2 & 1 & 19 & $<0.1$ & 1,4 & 0,18 \\
Seção 6 - C & 39,8 & 13,7 & 0,6 & 9,3 & 0,57 & 1,6 & 13,8 & 0,16 & 2,6 & 0,53 \\
Seção 7 - F & 21 & 6,2 & 0,3 & 14,9 & 1,9 & 1,1 & 26,6 & $<0.1$ & 0,95 & 1,7 \\
\hline
\end{tabular}


aos obtidos na fácies $\mathrm{C}$ (amarela), demonstraram menores valores de sílica. Os valores de $\mathrm{Al}_{2} \mathrm{O}_{3}$, por sua vez, apresentaram-se um pouco menores do que a rocha alterada. Em condições hidrolíticas, a sílica é lixiviada ao mesmo tempo em que os cátions básicos. Já o alumínio é praticamente retido em sua totalidade, ou seja, ele é pouco móvel (Pedro, 1969; Nahon, 1991). Os valores de $\mathrm{Fe}_{2} \mathrm{O}_{3}$, nessa fácies, são bem superiores aos encontrados na rocha alterada, indicando um ambiente de saturação sazonal dos sedimentos pela água para a remobilização do ferro, que se desloca até encontrar um ambiente aeróbico onde reoxida e precipita (Kämpf \& Curi, 2000).

Os valores químicos indicam que essas fácies já estiveram submetidas às freqüentes oscilações do lençol freático, com exportação da sílica e segregação do ferro.

Em relação à fácies $\mathrm{D}(\mathrm{Llv})$, os valores de $\mathrm{SiO}_{2}, \mathrm{Al}_{2} \mathrm{O}_{3}$ e $\mathrm{Fe}_{2} \mathrm{O}_{3}$ apresentaram grande similaridade com os valores obtidos na rocha alterada, principalmente na Llv das seções 1,3 e 4 . As cores avermelhadas nos solos e sedimentos devem-se à presença de hematita, que mascara a presença da goethita (Kämpf \& Schwertmann, 1983; Torrent et al., 1983). A cor amarelada, por sua vez, é devida à goethita e expressa a ausência de hematita. Não há evidências para a transformação no estado sólido de goethita em hematita por desidratação, nem o inverso por hidratação (Kämpf \& Curi, 2000), como sugeriu Lund para a transformação dos sedimentos vermelhos em amarelos na Lapa do Sumidouro.

\section{Dinâmica sedimentar e cronologia}

Na seção 2, a fácies A (Bgr) representa a primeira fácies deposicional, pois se encontra na base da pilha sedimentar e assentada diretamente sobre o piso calcário. É provável que essa fácies pertença ao mesmo processo deposicional que a fácies B (Bse), que teve uma gradação inversa dos clastos, ou seja, ocorreu um aumento da energia do fluxo da base para o topo, durante os processos de sedimentação. As fácies A e B apresentam características de pouco transporte e de deposição rápida. Essas duas fácies não foram identificadas por Lund, em 1844.

Na seção 1 é possível constatar que a fácies A encontra-se em posição inferior à capa estalagmítica e certamente pertenceu ao pacote sedimentar que serviu de base para a formação dessa capa. O contato entre a Bgr e a deposição química, no entanto, não é claro, em função da ocorrência de um episódio erosivo. Datação ${ }^{230} \mathrm{Th} /$ ${ }^{234} \mathrm{U}$ em fragmento dessa capa estalagmítica possibilitou o estabelecimento de uma idade mínima de 238.346 $\$ 8.770$ anos (SUMC-03) para a fácies A (Tabela 3). Essa capa teve como fonte um escorrimento de calcita localizado na porção superior do conduto, datado em $246.532 \pm 3.925$ anos (SUMC-02).

Os registros sedimentares demonstram a subsequente deposição da fácies $\mathrm{C}$ (Lma). Isso pode ser constatado na seção 2 , onde essa fácies encontra-se assentada diretamente sobre a fácies B. A deposição da fácies C, na seção 1, ocorreu sobre uma capa estalagmítica datada em 238.346 \pm 8.770 anos (SUMC-03), idade máxima admitida para essa fácies. A fácies $\mathrm{C}$, nas seções 2 e 3, foi submetida a uma nítida fase erosiva anterior à deposição da fácies D (Llv). Na seção 2, a fácies D preenche cavidades de erosão existentes no topo da fácies C. Na seção 3, a laminação da fácies D apresenta-se inclinada, acompanhando a superfície (irregular) de erosão do topo da fácies $\mathrm{C}$.

Em seguida foi sedimentada a fácies D, como demonstrado na seção 2, constatando-se que as fácies lamosas amarela (C) e vermelha (D) foram depositadas em momentos distintos, ou seja, os sedimentos amarelos não representam uma transformação do sedimento vermelho, como desejava Lund. Na seção 4 também ficou evidente que os episódios de deposição das fácies C e D não são sincrônicos, pois uma capa estalagmítica separa as duas fácies.

Foram parcialmente desmontados e analisados (in situ) importantes volumes das fácies C e D, não tendo

Tabela 3. Valores e idades (em anos) obtidos através de análises pela Série ${ }^{230} \mathrm{Th} /{ }^{234} \mathrm{U}$ (topo) e ${ }^{14} \mathrm{C}$ (base).

Table 3. Values and ages (in years) obtained from ${ }^{230} \mathrm{Th} / 234 \mathrm{U}$ (top) and ${ }^{14} \mathrm{C}$ (base) analyses.

\begin{tabular}{|c|c|c|c|c|c|c|c|}
\hline Amostra & $\begin{array}{l}{ }^{238} \mathrm{U} \\
(\mathrm{ppb})\end{array}$ & $\begin{array}{l}{ }^{232} \mathrm{Th} \\
\text { (ppt) }\end{array}$ & $\begin{array}{c}{ }^{234} U \\
\text { (medida) }\end{array}$ & $\begin{array}{l}{\left[{ }^{230} \mathrm{Th} /{ }^{238} \mathrm{U}\right.} \\
\text { (atividade) ] }\end{array}$ & $\begin{array}{c}\left.{ }^{230} \mathrm{Th} /{ }^{232} \mathrm{Th}\right] \\
(\mathrm{ppm})\end{array}$ & $\begin{array}{c}\text { Idade } \\
\text { (não corr.) }\end{array}$ & $\begin{array}{l}\text { Idade } \\
\text { (corr.) }\end{array}$ \\
\hline Sumc-01 & 135,9 & 372,7 & 354,6 & 0,2025 & 12,0 & $17.563 \pm 173$ & $11.459 \pm 3.07$ \\
\hline Sumc-02 & 106,4 & 684,9 & 341,2 & 1,2853 & Infinity & $246.532 \pm 3.92$ & $246.532 \pm 3.92$ \\
\hline Sumc-03 & 50,2 & 449,4 & 227,7 & 1,1470 & 175,0 & $240.544 \pm 8.89$ & $238.346 \pm 8.77$ \\
\hline $789 A$ & 211,6 & 11257,5 & 767,1 & 0,1409 & 43,7 & $9.021 \pm 114$ & $8.150 \pm 450$ \\
\hline $789 B$ & 289,5 & 15688,6 & 767,0 & 0,1339 & 40,8 & $8.561 \pm 101$ & $7.674 \pm 456$ \\
\hline \multicolumn{2}{|c|}{ Amostra } & \multicolumn{2}{|c|}{ Código } & \multicolumn{2}{|c|}{$\begin{array}{c}\text { Idade radiocarbônica } \\
\text { (anos AP) }\end{array}$} & \multicolumn{2}{|c|}{ Idade calibrada (anos AP) } \\
\hline \multicolumn{2}{|c|}{789 CHARC } & \multicolumn{2}{|c|}{ Beta-172186 } & \multicolumn{2}{|c|}{$7.650 \pm 50$} & \multicolumn{2}{|c|}{$8.530-8.370$} \\
\hline \multicolumn{2}{|c|}{789 SHELL } & \multicolumn{2}{|c|}{ Beta-172187 } & \multicolumn{2}{|c|}{$8.960 \pm 50$} & \multicolumn{2}{|c|}{$10.220-10.100$ e $10.090-9.920$} \\
\hline \multicolumn{2}{|c|}{ ZMUCBR247 } & \multicolumn{2}{|c|}{ Beta-174730 } & \multicolumn{2}{|c|}{$7.680 \pm 40$} & \multicolumn{2}{|c|}{$8.540-8.390$} \\
\hline \multicolumn{2}{|c|}{ ZMUCBR321 } & \multicolumn{2}{|c|}{ Beta-174732 } & \multicolumn{2}{|c|}{$7.590 \pm 80$} & \multicolumn{2}{|c|}{$8.530-8.200$} \\
\hline
\end{tabular}


sido registrado nenhum conteúdo fossilífero. Essas duas fácies encontradas na caverna são provavelmente originadas da cobertura de alteração da rocha filítica (zona epicárstica - área de contato rocha calcária e o filito alterado), assentada acima do maciço da caverna e introduzidas através de fendas alargadas existentes nos níveis superiores da caverna, mas que não esteve exposta na superfície do relevo cárstico (nível inferior da cobertura de alteração). A falta de laminação na fácies $C$ pode estar relacionada a fluxos gravitacionais rápidos. Já a laminação observada na fácies D indica um possível depósito originado de plumas de sedimentos em suspensão depositados sob baixas velocidades de fluxo. A possibilidade de Lund ter encontrado fósseis nas fácies $\mathrm{C}$ e $\mathrm{D}$ analisadas é mínima. Isso só seria possível através de deposições fossilíferas secundárias.

A granulometria mais grosseira e a maior lixiviação dos óxidos indicaram que a fácies E (Alc), que também apresenta uma cor vermelha, foi possivelmente originada da cobertura de solos, tendo sido introduzida e redistribuída na caverna pelo lençol freático, através de leques aluviais, ou seja, em conectividade com a superfície cárstica. O contato lateral da fácies $\mathrm{E}$ ( seção 5) com o escorrimento de calcita, coloca essa fácies com idade inferior a $11.459(+) 3.017(-) 2.953$ anos (SUMC- 01), tendo em vista que o referido espeleotema foi utilizado como suporte lateral para sua deposição. Nessa fácies também não foi identificado material fossílifero. No entanto, o volume de sedimento dessa fácies é muito restrito na caverna (só ocorre na seção 5). Essa fácies pode ser a descrita por Lund como argila vermelha original da caverna, onde foram identificados somente ossos de cervídeos. A fácies E, posteriormente, foi marcada por uma fase erosiva, seguida pela formação de uma nova geração de sedimentos químicos, de idade inferior a 11.459 (+)3.017(-) 2.953 anos (SUMC- 01). Essa geração mais recente de espeleotema não apresenta indícios de atuação de processos erosivos e de dissolução.

As presenças de conchas, fragmentos de ossos e carvão vegetal, indicam que a fácies $\mathrm{F}$ (Alb) é originada da parte externa da caverna, tendo sido introduzida via sumidouro. Uma amostra (Figura 4) fácies F, possibilitou a datação mínima de $8.150 \pm 450$ anos $(789 \mathrm{~A})$ para os sedimentos revolvidos (presença de conchas e carvão) abaixo da capa, contendo ossos indiscriminados. Já a amostra posicionada acima (789B), apresentou uma idade aparentemente mais recente ( $7.674 \pm 456$ anos), mas que tecnicamente está dentro da mesma faixa de idade da amostra 789A. Em seu relato de 1844, Lund identificou um sedimento amarelo-acinzentado sem manchas, mas com grande conteúdo de conchas, contendo localmente uma crosta estalagmítica. Essa descrição é concordante com as características da amostra 789. Dessa camada foi exumada a maior parte dos ossos humanos, como também os restos da fauna extinta (Lund, 1844). De todos os sedimentos descritos e analisados por Lund no Sumidouro, somente nesse é citada a existência de uma capa estalagmítica. Se a amostra 789 capeou o sedimento descrito por Lund, teríamos uma idade mínima corrigida de $8.150 \pm 450$ anos para os sedimentos com ossos humanos misturados a ossos da fauna extinta.

Essa amostra também forneceu mais duas datações, através de um fragmento de carvão e de conchas incrustadas na base da capa estalagmítica. O carvão (BR789CHARC) apresentou uma idade radiocarbônica calibrada de 8.530 a 8.370 anos AP (Beta - 172186), ou seja, concordante com as idades obtidas via ${ }^{230} \mathrm{Th} / 234 \mathrm{U}$. A idade radiocarbônica calibrada dos fragmentos de conchas (BR789SHELL), de 10.220 a 10.100 anos AP (Beta 172187) é um pouco mais antiga que as demais, demonstrando um possível revolvimento de material de idade mais antiga para níveis mais superficiais. A datação de conchas via ${ }^{14} \mathrm{C}$ também pode apresentar contaminação por carbono mais antigo ou mais jovem, dependendo do contaminante dissolvido e introduzido na amostra (Lowe \& Walker, 1997).

\section{A entrada dos ossos na caverna}

A planta da caverna (Figura 2) indica a existência de duas entradas conectadas com a superfície do relevo. A entrada superior (sul) não apresenta boas condições para o transporte de restos de animais para o interior da caverna, tendo em vista que sua bacia de captação é muito restrita e só em cheias excepcionais a lagoa atinge essa entrada. Animais maiores também teriam dificuldades de acesso, já que o teto dessa entrada é rebaixado. Os cinco modos de entrada dos ossos na caverna, proposto por Lund, poderiam ocorrer de forma ocasional nessa entrada, envolvendo particularmente animais de médio e pequeno porte.

A entrada inferior (norte) é representada por um conduto estreito, que funciona como um sumidouro da lagoa, juntamente com outros pontos de absorção não penetráveis ao homem. Em função das pequenas dimensões dessa entrada $(50 \times 50 \mathrm{~cm})$, a introdução de cadáveres de animais de médio e grande porte, como aqueles escavados por Lund, seria muito difícil por essa via. Somente ossos isolados poderiam ser introduzidos no sumidouro.

Durante os trabalhos topográficos foi constatado que o limite NW da caverna é constituído por uma seqüência de abatimentos recentes que, presumivelmente, obstruiu um acesso mais amplo à mesma. Esse fato é corroborado pela explosão da entrada da caverna, em 1980 ou 1981. Essa detonação, confirmada por alguns moradores locais, foi clandestina e visava o entupimento do sumidouro e a perenização da lagoa. Admitida a existência dessa conexão mais ampla com a superfície, o carreamento de cadáveres e restos esqueletais pelo fluxo da água vinda do sumidouro (processo 5 proposto por Lund) foi certamente o processo 
mais importante, sendo que os demais processos só poderiam ocorrer com o rebaixamento total do nível da lagoa. Lund (1844), em nenhum momento, descreveu a ocorrência de ossos de animais articulados durante suas escavações. Outro dado importante é que durante a análise do material fossilífero de animais encontrados por Lund na Lapa do Sumidouro foi constatada uma grande fragmentação dos ossos e a falta de esqueletos completos, sinalizando um ambiente sedimentar muito dinâmico, envolvendo transporte, abrasão e fragmentação dos ossos.

Constata-se, ainda, que no período de enchimento da lagoa e da caverna (normalmente em novembro), pode ser observado um fluxo unidirecional do lençol freático no sentido N-S, ou seja, do sumidouro em direção ao salão Lund, que parece conter uma insurgência difusa. Isto explicaria a concentração de fósseis escavados por Lund nesse salão, como também a falta de testemunhos sedimentares antigos nas paredes do setor norte, que certamente foram lavados e, em seguida, depositados no piso do salão Lund.

A entrada sul parece a mais favorável para a introdução dos corpos humanos. A condução de cadáveres pela entrada norte é improvável, mas, somente em períodos de seca prolongada, com o rebaixamento total da lagoa, os corpos poderiam ser ali introduzidos. $\mathrm{O}$ transporte de cadáveres em ambientes aquáticos tende a ocasionar uma rápida decomposição do tecido orgânico que envolve os ossos, levando à desarticulação (Behrensmeyer,1991). Ossos longos isolados e, particularmente, os 23 crânios relativamente bem preservados, achados por Lund no Sumidouro, não suportariam os diversos impactos ocasionados pelo fluxo hídrico nas paredes dos condutos, durante o percurso de aproximadamente $65 \mathrm{~m}$ até sua deposição no salão Lund. Crânios de vertebrados se comportam hidrodinâmicamente como depósitos de fundo, com tendência a ficarem soterrados após pouco ou nenhum transporte (Holz \& Simões, 2002).

A introdução de cadáveres humanos nos salões Lund e Diniz, via entrada sul, seria facilitada pela proximidade desses dois salões com essa entrada (menos de $5 \mathrm{~m}$, no salão Lund, e $8 \mathrm{~m}$ no salão Diniz). A entrada sul só é atingida pela lagoa do Sumidouro em cheias excepcionais, indicando que essa era uma área mais favorável para a utilização (cemitério ou descarte de cadáveres) pelos paleoíndios.

Durante a análise da coleção de esqueletos humanos do Sumidouro foram recolhidas mais duas amostras para datação. Um fragmento de carvão (ZMUCBR247), incrustado em um osso pós-craniano humano, apresentou uma idade radiocarbônica calibrada de 8.540 a 8.390 anos AP (Beta - 174730). Uma concha (ZMUCBR321) cimentada no meato auditivo de um crânio, por sua vez, apresentou uma idade radiocarbônica calibrada de 8.530 a 8.200 anos AP. Essas idades, juntamente com aquelas obtidas na amostra 789, reforçam a idade mínima calibrada de 8.000 anos para os remanescentes humanos da Lapa do Sumidouro. Esta idade mínima encontra-se dentro do período cronológico de outras idades radiocarbônicas calibradas para esqueletos humanos da região, concentradas entre 11.000 e 8.000 anos AP (Araújo et al., 2002; 2003). Não foi possível obter idades radiocarbônicas para remanescentes da fauna de vertebrados extintos na Lapa do Sumidouro. Recentemente, no entanto, obteve-se, na região, diversas datações radiocarbônicas e ${ }^{230} \mathrm{Th} /{ }^{234} \mathrm{U}$ desses remanescentes, que apresentaram idades calibradas entre 10.000 e 450.000 anos, indicando uma grande variação nas idades dos fósseis (Auler et al., 2003), mas reforçando a tese original de Lund da convivência de algumas espécies de megafauna (Scelidodon (Catonyx) cuvieri e Smilodon populator) com os paleoíndios (Neves \& Piló, 2003).

\section{CONCLUSÕES}

Datações via ${ }^{230} \mathrm{Th} /{ }^{234} \mathrm{U}$ possibilitaram identificar na Lapa do Sumidouro uma deposição de brecha com clastos (fácies A) com idade superior a 238.000 anos. Uma fácies vermelha (E) registrou uma idade máxima de aproximadamente 11.400 anos. Constatou-se pelo menos duas fases erosivas na caverna, uma com idade máxima de 238.000 anos e outra com idade máxima de 11.000 anos. As datações também possibilitaram o registro de dois episódios de sedimentação química na caverna: o mais antigo com cerca de 240.000 anos e um mais recente entre 11.000 e 8.000 anos.

Foram identificadas seis fácies sedimentares distintas (espacial e temporalmente) e não derivações originadas do sedimento vermelho devido à atuação do lençol freático, como propôs Lund (1844). Os dados químicos também indicaram que os sedimentos vermelhos e amarelos são distintos (não sincrônicos), e que os sedimentos amarelos com manchas pretas são mais antigos do que os vermelhos, que foram introduzidos após fases erosivas. As fácies C e D (amarela e vermelha, respectivamente) ter-se-iam originado do manto de alteração do filito, localizado na zona epicárstica, sem contato com a superfície do carste e por isso estéreis, sob o ponto de vista paleontológico. Duas fácies sedimentares (E e F) apresentaram indícios de possível conectividade com a superfície do relevo cárstico.

A entrada sul foi a mais favorável para a introdução de corpos humanos na caverna, ao passo que a maioria dos animais da fauna extinta e vivente teria sido introduzida via sumidouro (entrada norte).

As datações ${ }^{14} \mathrm{C}$ (AMS) em material aderido a ossos humanos indicaram uma idade mínima calib rada de cerca de 8.000 anos AP para os esqueletos humanos. As datações ${ }^{14} \mathrm{C}$ $\mathrm{e}^{230} \mathrm{Th} /{ }^{234} \mathrm{U}$ na amostra 789 também estabeleceram uma idade mínima corrigida de 8.000 anos para os sedimentos subjacentes (argila amarelada com conchas) com ossos humanos misturados a ossos da fauna extinta. 
As análises da dinâmica hídrica, dos depósitos sedimentares e da tafonomia, obtidas da Lapa do Sumidouro, fortalecem o argumento levantado pelo próprio Lund: ossos de idades diferentes poderiam ter sido removidos de seus locais de deposição primária e misturados nas argilas transformadas, gerando deposições fossilíferas secundárias e cronologicamente distintas.

\section{AGRADECIMENTOS}

Os recursos necessários para a pesquisa foram fornecidos pela FAPESP (WAN e LBP, Proc. n. 99/00670-7 e 00/149173) e pelo CNPq (ASA, proc. n. 540064/01-7). Agradecemos a Kim Aaris-Sørensen (MZUC) por facilitar nosso acesso à Coleção Lund e a Birgitte Holten e Michael Sterll pela ajuda na tradução dos documentos. Ao Grupo Bambuí de Pesquisas Espeleológicas - GBPE pela colaboração nos trabalhos de campo e na execução da topografia da caverna.

\section{REFERÊNCIAS}

Araujo, A.G.; Neves, W.A.; Piló, L.B. 2002. Paleoindian subsistence and technology in central Brazil: results from the new excavations at Boleiras rockshelter, Lagoa Santa. Current Research in the Pleistocene, 19: 4-6.

Araujo, A.G.M; Neves, W. \& Piló, L.P. 2003. Eventos de seca no Holoceno e suas implicações para o povoamento pré-histórico do Brasil Central. In: CONGRESSO DA ASSOCIAÇÃO BRASILEIRA DE ESTUDOS DO QUATERNÁRIO - ABEQUA, 9. 2003. Resumos, Recife, p. 273.

Auler, A.S.; Piló, L.B.; Smart, P.; Wang, X.; Neves, W.A.; Cheng, H. \& Edwards, L.E. 2003. Cronologia e processos de deposição da megafauna quaternária em cavernas brasileiras. In: CONGRESSO DA ASSOCIAÇÃO BRASILEIRA DE ESTUDOS DO QUATERNÁRIO - ABEQUA, 9. 2003. Resumos, Recife, p.28.

Behrensmeyer, A.K. 1991. Terrestrial vertebrate accumulations. In: P.A Allison \& D.E.G. Briggs. (eds.) Taphonomy: releasing the data locked in the fossil record. New York, Plenum Press, p.291-335.

Blum, M. \& Neves, W.A. 2002. O Modelo dos dois components biológicos principais: sua inserção nos eventos expansionistas do final do Pleistoceno e suas implicações para a origem do Homo Sapiens. O Carste, 14(1):42-49.

Hansen, S. 1888. Lagoa Santa racen. En anthropologisk undersögelse af jordfundne menneskelevninger fra brasilianske huler. Med et tillaeg om det jordfundne menneske fra Pontimelo, Rio de Arrecifes, La Plata. E Museo Lundii, 1:1-34.

Holten, B. \& Sterll, M. 1999. Uma carta reencontrada - relatório conclusivo das escavações feitas em Lagoa Santa pelo naturalista P.W. Lund. Revista do Instituto Histórico e Geográfico Brasileiro, 160(403): 371-398.

Holz, M. \& Simões, M.G. 2002. Elementos fundamentais de tafonomia. $1^{\text {a }}$ ed. Porto Alegre, Editora da Universidade do Rio Grande do Sul, 231p.

Hrdlicka, A. 1912. Early man in South America. Bureau of American Ethnology, 52:153-392.

Kämpf, E. \& Curi, N. 2000. Óxidos de ferro: indicadores de ambientes pedogenéticos e geoquímicos. In: Novais, R. F. de;
Alvarez, V. H. \& Schaefer, C. E. G. R. (eds.) Tópicos em ciência do solo, Sociedade Brasileira de Ciência do Solo, 1, p.107-138.

Kämpf, E. \& Schwertmann, U. 1983. Relações entre óxidos de ferro e a cor em solos caoliníticos do Rio Grande do Sul. Revista Brasileira de Ciência do Solo, 7:27-31.

Kate, H. 1885. Sur les crânes de Lagoa Santa. Bulletins de la Société d'Anthropologie de Paris, 8:240-244.

Kos, A.M. 2001. Stratigraphy, sedimentary development and paleoenviromental context of a naturally accumulated pitfall cave deposit from southeastern Australia. Australian Journal of Earth Sciences, 48:621-632.

Laureano, F.V. 1998. O registro sedimentar clástico associado aos sistemas de cavernas Lapa Doce e Torrinha, Município de Iraquara, Chapada Diamantina (BA). Programa de Pós-graduação em Geoquímica e Geotectônica, Instituto de Geociências da Universidade de São Paulo, Dissertação de Mestrado, 98p.

Lowe, J.J. \& Walker, M.J.C. 1997. Reconstructing Quaternary Environments. $2^{\mathrm{a}}$ ed. England, Pearson Education Limited, 446p.

Lund, P.W. 1844. Notícia sobre ossadas humanas fósseis achadas numa caverna do Brasil. In: Paula Couto, C. de. (ed.). Memórias sobre a paleontologia brasileira, Instituto Nacional do Livro, p. 465-488.

Lund, P.W. 1845. Katalog over Professor Dr. P.W. Lund palaeontologiske Samling. 2. Afdeling Breccier. Zoological Museum of the University of Copenhagen Archives. Manuscrito não publicado.

Lütken, C.F. 1883. Exposition de quelques-uns des crânes et des autres ossements humains de Minas-Geraes dans le Brésil central découverts et déterrés par le feu Professeur P.W. Lund. In: CONGRÈS INTERNATIONAL DES AMÉRICANISTES, 1883, Copenhagen, Compte Rendus, p. 40.

Nahon, D.B. 1991. Introduction to the petrology of soils and chemical weathering. John Wiley \& Sons, 313p.

Neves, W.A. \& Piló, L.B. 2003. Solving Lund's dilemma: new AMS dates confirm that humans and megafauna coexisted at Lagoa Santa. Current Research in the Pleistocene, 20:57-60.

Neves, W.A. \& Pucciarelli, H.M. 1991. Morphological affinities of the first Americans: an exploratory analysis based on early South American human remains. Journal of Human Evolution, 21:261-273.

Palmer, A. N. 1991. Origin and morphology of limestones caves. Geological Society of America Bulletin, 103:1-21.

Paula Couto, C. de. 1950. Memórias sobre a paleontologia brasileira. Rio de Janeiro, Instituto Nacional do Livro, 589p.

Pedro, G. 1969. A alteração das rochas em condições superficiais (perimorfismo) - caracterização geoquímica dos processos fundamentais. Notícia Gemorfológica, 9(17):3 -14.

Piló, L.B. 1998. Morfologia cárstica e materiais constituintes: dinâmica e evolução da depressão poligonal Macacos-Baú. Programa de Pós-graduação em Geografia Física, Departamento de Geografia da Universidade de São Paulo, Tese de Doutoramento, $268 \mathrm{p}$.

Powell, J.F. \& Neves, W.A. 1999. Craniofacial morphology of the first americans: pattern and process in the peopling of the new world. Yearbook of Physical Anthropology, 42:153-188.

Quatrefages, A. 1881. L'Homme fossile de Lagoa Santa en Brésil et ses descendants actuels. Comptes Rendus Academie des Sciences, 93: 882-884.

Reinhardt, J.T. 1888. De brasilianske knoglehuler og de i dem forekommende dyrelevninger. E Museo Lundii, 1, 1-56. 
Rivet, P. 1908. La race de Lagoa Santa chez les populations précolombiennes de l'Équateur. Bulletin et Mémoires de la Société de Anthropologie, 9:209-268.

Soto-Heim, P. 1994. Les hommes de Lagoa Santa (Brésil). Caractères anthropologiques et position parmi d'autres populations paléoindiennes d'Amerique. L'Anthropologie, 98:81-109.
Torrent, J.; Schwertmann, U.; Fechter, H. \& Alferez, J. 1983. Quantitative relationship between soil color and hematite content. Soil Science, 136:354-358.

Received August, 2003; accepted, April, 2004. 